\title{
Authoring Esteem: Writing About Vicarious and Personal Life Story Chapters Boosts State Self-Esteem
}

\author{
Dorthe Kirkegaard Thomsen $^{1}$ (D) , Stefan Pfattheicher ${ }^{1}$ (D) , William L. Dunlop ${ }^{1,2 \dagger}$ \\ [1] Department of Psychology and Behavioural Sciences, Aarhus University, Aarhus, Denmark. [2] Department of \\ Psychology, University of California, Riverside, CA, USA. \\ ${ }^{\dagger}$ Author deceased prior to publication of this paper.
}

Personality Science, 2021, Vol. 2, Article e7017, https://doi.org/10.5964/ps.7017

Received: 2021-06-27 • Accepted: 2021-10-12 • Published (VoR): 2021-12-23

Handling Editor: Martina Hřebíčková, Institute of Psychology, Czech Academy of Sciences, Brno, Czech Republic

Reviewing: Round 1 - Tilmann Habermas; Anonymous \#1. No open reviews are available.

Corresponding Author: Dorthe Kirkegaard Thomsen, Department of Psychology and Behavioural Sciences, Bartholins Allé 9, 8000 Aarhus, Denmark. E-mail: dorthet@psy.au.dk

Supplementary Materials: Materials, Preregistration [see Index of Supplementary Materials]

\begin{abstract}
Constructing personal life stories carries benefits for psychological adjustment. We examined whether writing about the life stories of parents (i.e., vicarious life stories) hold similar advantages. In Study 1, we adapted an established experimental paradigm to an online format. Participants wrote either about personal life story chapters or about famous persons (control condition) and completed pre- and post-measures of state self-esteem. We found the predicted interaction as selfesteem increased in the chapter but not in the control condition. In Studies 2 and 3, we added the critical condition of writing about vicarious chapters. Study 2 did not find the predicted interaction. Instead, all three conditions increased in self-esteem. Study 3, which used a new neutral control task (writing about historical events), showed that the two chapter conditions, but not the control condition, increased in self-esteem. This suggests that authoring life stories for both oneself and close others momentarily boosts self-esteem.
\end{abstract}

\section{Keywords}

vicarious life stories, self-esteem, experimental 


\section{Relevance Statement}

As individuals interact with parents, friends, and romantic partners, they hear their stories. These stories help individuals construct life stories for close others: Coherent narratives of the close other's remembered past, lived present, and imagined future. Such vicarious life stories aid complex individualized perspective-taking and shape individuals' personal life stories (i.e., narrative identities). Research has established relations between qualities of vicarious life stories and well-being. However, to further understanding of vicarious life stories and their presumed benefits, we need experimental studies examining causal relations between vicarious life stories and positive outcomes. In this paper, we report the first experimental studies on vicarious life stories. We demonstrate that writing about vicarious life stories for parents increase state self-esteem. Given this promising result, we suggest using our experimental paradigm to further illuminate the benefits of vicarious life stories. Conditions can be varied to study the micro-processes involved in the adaptive effects of life story construction, such as positive meaning-making and emotional exploration. The results from this research program may broaden existing narrative interventions, which focus on personal life stories, to include vicarious life stories.

\section{Key Insights}

- Writing about vicarious and personal life stories increases state self-esteem.

- This effect is unrelated to the emotional tone and self-event connections in chapters.

- $\quad$ Constructing vicarious life stories contributes to psychological adjustment.

Personal life stories, or narrative identity, capture the intimate and uniquely personal way individuals make sense of themselves and their lives, through time (Habermas \& Bluck, 2000; McAdams, 1996). The last 30 years has witnessed a sizable uptick in the interest personality psychologists have exhibited in life stories (Adler et al., 2016; Dunlop, 2021; McLean et al., 2007). The power of narrating personal experiences is highlighted in the range of psychological interventions emphasizing life stories (Pinquart \& Forstmeier, 2012; Thomsen et al., 2021; White \& Epston, 1990). From a personality perspective, such interventions are concerned with how narrative identity can be targeted to improve adjustment.

In the current studies, we entertain the following question: does storying close others' lives carry similar benefits? This work is grounded in the growing literature on vicarious life stories (Thomsen \& Pillemer, 2017) and intergenerational narratives (McLean, 2015; Merrill \& Fivush, 2016; Pratt et al., 2008). Adopting and modifying an established experimental paradigm that has shown increased state self-esteem after writing about personal life story chapters (Steiner et al., 2019), we examined whether writing about vicarious life story chapters of parents similarly impacted self-esteem. We chose self-esteem as our primary outcome because it refers to the overall evaluation of 
the self, which is associated with emotional benefits valued by individuals (Baumeister, 1999). In our first study, we adapted the paradigm to an online format and tested whether the effect authoring personal chapters exhibited on self-esteem was still present. Having established the validity of our online experimental paradigm in Study 1, in Studies 2 and 3, we added the critical condition of writing about the vicarious life story chapters of parents and tested whether similar positive effects on self-esteem were found. We reasoned that constructing life stories for close others brings continuity and meaning to their lives and that inhabiting a social world, where both individual's own and their close others' lives make sense, brings self-esteem. The present work has the central aim of experimentally examining the benefits of vicarious life stories, moving beyond correlational studies of how qualities of vicarious stories relate to well-being.

\section{Capturing the Stories of Our Lives}

Lives are complicated things. The sum total of all previous experiences and self-representations would be enough to make the heads of even the most well-adjusted among us spin (Dunlop, 2015). Thankfully, adults possess the ability to make sense of the self over time, via the organizing principle of narrative (Bruner, 1990). Such narrative processing culminates in the authoring of a life story wherein representations of the personal past, present, and future are brought together. The construction of such a story affords individuals a sense of unity, meaning, and direction. For this reason, identity itself has been suggested to take the form of a story, or a narrative identity (McAdams, 1996; McAdams \& McLean, 2013).

To assess features of life stories, researchers often rely on the Life Story Interview (LSI; McAdams, 2008). In the LSI, participants first identify chapters and then elaborate on selected key scenes such as high points. Life story chapters are "extended time periods with perceived beginnings and endings that are considered important to how the person has become who she or he is today" (Thomsen et al., 2016, p. 144) and represent extended narratives of identity-salient life periods. Through the construction of chapters, experiences are organized and the overall coherence of life stories is enhanced (Thomsen, 2009).

\section{Capturing the Stories of Close Others' Lives}

The lives of close others, such as parents and romantic partners, are likely no less complicated than our own. When individuals strive to make sense of close others' lives, they similarly employ narratives. This has been studied under various headings, including intergenerational narratives (McLean, 2015; Merrill \& Fivush, 2016), vicarious memories (Pillemer et al., 2015), and vicarious life stories (Thomsen \& Pillemer, 2017). When individuals construct vicarious life stories, they organize chapters and key scenes to create a coherent story of that other person's past, present, and future. As such, 
forming vicarious life stories can be conceived as a form of person perception (Harake et al., 2020a). Consistent with the idea that individuals' perceptions of others partly reflect their own construals, studies indicate that vicarious life stories are colored by personal life stories. That being said, vicarious life stories are far more than mere projections of one's own story, as consensus has been found between individuals' personal stories and the vicarious stories close others attribute to them (Harake et al., 2020a; Panattoni \& Thomsen, 2018; Thomsen et al., 2020).

Researchers have speculated about the potential functions of vicarious life stories. The construction of vicarious life stories contributes to the individualization of the protagonist and more sophisticated perspective-taking. As such, vicarious life stories may aid in the sense-making of close others' actions, intentions, and emotions (Habermas, 2019; Panattoni \& Thomsen, 2018). This way, individuals can move beyond situation-specific behaviors, intentions, and emotions to broader inferences about the meaning the situation holds seen through the lens of the close other's life story. There is reason to suspect that such life story understanding of close others fosters relationship benefits (Harake et al., 2020a; Panattoni \& Thomsen, 2018).

Vicarious life stories may also provide scaffolding for personal life stories (McLean, 2015; Reese et al., 2017; Thomsen \& Vedel, 2019). For example, considering the life stories of parents may provide adult children with impetus for shaping their personal life stories in ways that both parallel and diverge from parents' narratives (e.g., "knowing the story of how my mother struggled with her first job but now values this experience, makes me think that I will someday look back differently on my current job problems"). Vicarious life stories dramatically expand the array of interpretations and behaviors available to individuals (Pillemer et al., 2015).

\section{Assessment, Intervention, or Both?}

There are at least two ways in which personal life stories may be associated with psychological adjustment, which includes aspects of well-being such as belief in own worth, meaning, and positive affect (Diener et al., 2003; Ryff, 2014). The first pertains to individual differences in the structure and content of life stories. The second pertains to the impact of producing these life stories themselves.

With respect to the first, there is a sizable literature in which reliably coded and quantified elements of key scenes and chapters have been associated with a variety of health and well-being indicators, both cross-sectionally and prospectively (for reviews see Adler et al., 2016; Dunlop, 2021). For example, redemption (present when a story begins negatively and ends positively; McAdams et al, 2001) corresponds concurrently with mental health (Dunlop, 2021). Mirroring this research, studies demonstrate that the structure and content of vicarious stories relate to well-being (Harake et al., 2020b; Merrill \& Fivush, 2016; Thomsen \& Vedel, 2019). For example, Lind and Thomsen (2018) found that more positive meaning in vicarious life stories for parents was related to 
more healthy identity, including a sense of being whole and certain about oneself. In summary, the stories individuals construct pertaining to both the self and others relate to psychological adjustment.

With respect to the second, telling life stories may represent a form of intervention (Thomsen et al., 2021). For example, the expressive writing paradigm, wherein participants are instructed to write about personal experiences repeatedly over several days, has been found to reduce the number of subsequent health complaints (Frattaroli, 2006; Pennebaker \& Seagal, 1999). Similarly, life review therapy has been noted to reduce depressive symptoms (Pinquart \& Forstmeier, 2012), narrating memories help emotional processing (Pasupathi et al., 2017; Smorti \& Fioretti, 2016), and recalling experiences concerning current romantic partners has been found to enhance relationship warmth (Alea \& Bluck, 2007). The essence of this research is that the process of reflecting on and storying experiences may contribute to flourishing.

More closely related to the present studies, researchers have examined the positive impact of life story reflection (Steiner et al., 2019; Turner et al., 2021). Over three experiments, Steiner and colleagues (2019) prompted participants to write about either 1) four personal life story chapters, or 2) four famous Americans (these studies were conducted in the United States). Administering measures of mood, state-based self-concept clarity, and state-based self-esteem both before and after these tasks, Steiner and colleagues noted that, relative to those who wrote about famous Americans, those who wrote about their own life story chapters demonstrated greater gains in self-esteem. Across studies, the increase in state self-esteem was unrelated with chapter content. Thus, it appeared to matter little whether participants disclosed relatively positive or negative chapters, suggesting that it is the process of narration per se rather than the type of narration that is key to the effect. On the whole, these extant works suggest that crafting a story about the self is associated with heightened psychological adjustment (McAdams, 2013).

Inspired by the growing literature on vicarious stories, we were interested in determining whether the process of storying close others' lives may similarly benefit narrators. As crafting narratives organizes diverse experiences into a coherent whole, reflecting on the life stories of close others may provide individuals with a sense that they understand the close other, contributing to self-esteem. Furthermore, given that vicarious life stories for close others are intertwined with personal life stories (Panattoni et al., 2021), reflecting on close others' life stories may indirectly bring order and meaning to individuals' personal life stories, which again, may carry benefits for self-esteem. Collecting data on the potential advantages of narrating close others' lives can help clarify the adaptive functions of constructing vicarious life stories and inspire narrative interventions. 


\section{The Present Studies}

We extend previous experimental work on personal life stories (Jones et al., 2018; Steiner et al., 2019) to determine whether writing about vicarious life stories similarly impacts state self-esteem. In Study 1, we modified and determined the validity of the in-person assessment procedure reported in Steiner et al. (2019) for administration via personal computer. Having demonstrated the efficacy of such an approach, in Studies 2 and 3, we then compared the impact of a vicarious life story chapter task, in which participants were instructed to write about the chapters of a parent, with a personal chapter task and a control condition. We focused on vicarious life stories of parents because these have been emphasized as crucial for psychological adaptation (Merrill \& Fivush, 2016; Reese et al., 2017; Thomsen et al., 2020). In all three studies, measures of mood and state-based self-esteem were administered both before and after the writing tasks. We predicted that participants who wrote about chapters in their parents' and their own life stories would increase in state self-esteem compared to the control condition.

\section{Study 1}

In the original study using the presently adopted experimental paradigm, participants were invited to the lab in groups to write about their life story chapters (Steiner et al., 2019). We adapted the procedure to an online format to test whether effects would remain when participants wrote about their chapters in a place and time of their own choosing. This adaptation offered pragmatic benefits insofar as it allowed for testing of more participants with fewer resources-which was needed when adding the new condition of main interest (in Studies 2 and 3): Writing about vicarious life story chapters. This extension was also motivated by Frattaroli's (2006) meta-analysis indicating that effects of expressive writing were larger when participants completed the writing task at home (as compared to on-campus laboratories). As such, Study 1 served as a platform for the development of the experimental paradigm to be used in Studies 2 and 3. If effects were present when our intervention was administered online, our life story task would become an attractive possibility to internet-based interventions, which are winning terrain (Johansson \& Andersson, 2012).

Save for the adaption to the online format, we designed the study to match the previous studies: The experimental group wrote about four personal life story chapters, whereas the control group wrote about four famous persons. State self-esteem and mood were measured both before and after the writing task. We anticipated an interaction between condition and time, such that the group writing about personal chapters would demonstrate an increase in self-esteem, relative to the control group. As was the case with the work of Steiner et al. (2019), we included measures of mood to examine whether effects on self-esteem were explained by mood ${ }^{1}$. 


\section{Method}

Data scripts and materials can be found in Supplementary Materials. The full data set is not available, as national data sharing rules do not presently allow this.

\section{Participants and Recruitment}

Demographic information for the 254 participants are shown in Table 1 (135 in the personal chapter condition; note that we only analyzed data from participants who had four valid chapter/person descriptions and complete self-esteem data, and excluded 70 incomplete responses). The sample size was decided to allow detection of a small-medium effect size (of the predicted within-between interaction; $f>.10$, power $=.90$, correlation among repeated measures .50 , alpha-level .05 , two-tailed), building on the main analysis from the prior study (Steiner et al., 2019). Participants were recruited from a Danish University, where the students participated as a part of a research methods course. Each student was asked to enroll two additional participants over the age of 40 (to ensure spread in age range), a woman and a man.

\section{Materials and Procedure}

Participants were randomized to two conditions (see details below). They were instructed to open the survey when they had one hour of uninterrupted time and complete it in one sitting.

The first part of the survey included a request for informed consent and demographic information. The second part of the survey included scales measuring current mood and state self-esteem (in that order). We used the state-based Positive and Negative Affect Schedule (Watson et al., 1988) to measure mood, which contains 10 items measuring positive affect and 10 items measuring negative affect, each rated on a 5-point scale (with higher scores indicating more affect; Cronbach's alphas $>.85$ ). To measure state self-esteem, we used an adapted version of Rosenberg's (1965) self-esteem scale. The original scale includes 10 items rated on a 1-4 point scale. Inspired by Çili and Stopa (2015), we adapted the scale to a state format by modifying the wording of the instruction and items to capture how participants felt about themselves right now (e.g., the instruction asked participants to "rate the items according to how you feel about yourself right now at the present moment", and item 2 was adapted to read: "I think I am no good at all"). Higher scores reflect higher state self-esteem (Cronbach's alphas $>.90$ ).

In the third part, participants were either instructed to write about four chapters in their life stories or four famous persons (see Supplementary Materials for full instruc-

\footnotetext{
1) In Studies 1 and 2, we included a measure of state self-concept clarity (Campbell et al., 1996), but similar to the previous three studies (Steiner et al., 2019) we found no significant effects and left it out of Study 3. Hence, we do not report analyses for this scale here (see Supplementary Materials).
} 
Table 1

Demographics for Participants in Studies 1-3

\begin{tabular}{|c|c|c|c|}
\hline Variable & Study 1 & Study 2 & Study 3 \\
\hline \multicolumn{4}{|l|}{ Gender } \\
\hline Woman & 182 & 162 & 194 \\
\hline Man & 72 & 85 & 89 \\
\hline Missing response & 0 & 0 & 1 \\
\hline \multicolumn{4}{|l|}{ Age (in years) } \\
\hline$M$ & 36.87 & 30.75 & 29.90 \\
\hline$S D$ & 16.39 & 13.86 & 13.05 \\
\hline Range & $20-75$ & $19-81$ & $18-68$ \\
\hline \multicolumn{4}{|l|}{ Employment status } \\
\hline Student & 148 & 166 & 211 \\
\hline In full- or part-time work & 95 & 66 & 59 \\
\hline Unemployed & 1 & 6 & 5 \\
\hline Retired & 10 & 9 & 8 \\
\hline Missing response & 0 & 0 & 1 \\
\hline \multicolumn{4}{|l|}{ Highest level of education } \\
\hline Elementary school & 6 & 3 & 5 \\
\hline Further professional training & 6 & 3 & 11 \\
\hline High school or equivalent & 137 & 144 & 189 \\
\hline $3-4$ years of further education & 55 & 33 & 40 \\
\hline University degree & 50 & 64 & 39 \\
\hline \multicolumn{4}{|l|}{ Ethnical background } \\
\hline Danish ethnical background & 228 & 234 & 272 \\
\hline Other ethnical background & 26 & 12 & 9 \\
\hline Did not wish to reply & 0 & 1 & 0 \\
\hline Missing response & 0 & 0 & 3 \\
\hline
\end{tabular}

Note. Except for Age all values are frequencies.

tions). For the personal chapter group, instructions invited participants to think back on their entire life course and identify the four most important chapters from their life stories. Chapters were described as extended periods in life and examples were provided. In the case of each chapter, participants were invited to include information about people, places and activities; to consider how the chapter related to their entire life story, including causes, consequences, and themes; and to spend at least 10 minutes describing this period in their lives. They were provided with text fields to describe the chapter, to note what the chapter said about who they were as a person, and to indicate how it related to other chapters. Furthermore, for each chapter participant 
answered the following four questions: "To what degree would you describe the chapter as positive/negative?" and "Did the chapter change you in a positive/negative way?", all rated on a 5-point Likert-type scale ranging from 1 (not at all) to 5 (to a very high degree; Jensen et al., 2020) ${ }^{2}$.

For the four famous persons group, participants were asked to identify four famous persons from any point in history, and examples were provided. They were instructed that they could choose any famous person they wished. For each famous person they were instructed to include information about the people, places, and activities they associated with the person and to spend at least 10 minutes writing. To match the personal chapter condition, participants were provided with text fields to describe the famous person, to describe why they thought the person had become famous, and to describe whether the famous person reminded them of other famous persons and what possible connections were. They then answered the following four questions: "To what degree would this person be evaluated positively/negatively?" and "Has the evaluation of this person changed positively/negatively over time?", all rated on 5-point Likert-type scale ranging from 1 (not at all) to 5 (to a very high degree). After completing descriptions and ratings for the four famous persons, participants were asked to rate their degree of identification with each person on the following question: "I think the person is similar to me on some points" on a 5-point Likert-type scale ranging from 1 (do not agree at all) to 5 (totally agree). The four items were included to explore whether higher degree of identification would relate to changes in state self-esteem.

Finally, in the fourth part, participants again completed scales measuring mood and state self-esteem. They were thanked for their participation and debriefed.

\section{Results and Discussion}

To test the main hypothesis that writing about personal chapters would increase state self-esteem, we ran a mixed two-way ANOVA (group: personal chapters vs. famous persons; time: before vs. after). There was a significant main effect of time, no significant effect of group, and importantly, the predicted interaction (Table 2 and Figure 1). We examined this interaction by a planned comparison of pre and post scores on state self-esteem within each condition. For the chapter group, there was a significant increase in self-esteem, $t(134)=4.27, p<.001, d=-.37,95 \%$ CI [-.54, -.19]. For the famous person group, the effect was in the same direction but did not reach conventional levels of significance, $t(118)=1.81, p=.073, d=-.17,95 \% \mathrm{CI}[-.35, .02]$. When controlling for mood change (via the PANAS) ${ }^{3}$, the interaction remained significant, $F(1,250)=3.94, p=.048$,

2) In Study 1, we explored whether content-coded emotional tone and positive/negative self-event connections were related to effects on self-esteem. We did not find any significant relations between how participants described their chapters in terms of emotional tone and self-event connections, and improvements of self-esteem. For more details on content-coding and analyses, see Supplementary Materials. 
$\eta_{\mathrm{p}}^{2}=.016$; effect of time: $F(1,250)=18.02, p<.001, \eta_{\mathrm{p}}^{2}=.067$; effect of group: $F(1,250)=$ $2.63, p=.106, \eta_{\mathrm{p}}^{2}=.010$.

\section{Table 2}

Means (SD) and ANOVA Statistics for State Self-Esteem Before and After the Experimental Manipulation in Studies $1-3$

\begin{tabular}{|c|c|c|c|c|c|}
\hline Study/Condition & $\begin{array}{c}\text { Self-esteem, } \\
\text { before } \\
M(S D)\end{array}$ & $\begin{array}{c}\text { Self-esteem, } \\
\text { after } \\
M(S D)\end{array}$ & Time & Condition & $\begin{array}{l}\text { Time } x \text { condition } \\
\text { interaction }\end{array}$ \\
\hline \multicolumn{6}{|l|}{ Study 1} \\
\hline Personal chapters & $33.54(5.48)$ & 34.76 (5.09) & $F(1,252)=19.48^{* *}$ & $F(1,252)=.44$ & $F(1,252)=5.37^{*}$ \\
\hline Famous persons & $34.38(5.15)$ & $34.76(5.26)$ & $\eta_{\mathrm{p}}^{2}=.07[.02, .14]$ & $\eta_{\mathrm{p}}^{2}=.002[.00, .03]$ & $\eta_{\mathrm{p}}^{2}=.02[.00, .07]$ \\
\hline \multicolumn{6}{|l|}{ Study 2} \\
\hline Personal chapters & $33.51(5.35)$ & 34.38 (5.39) & $F(1,244)=26.25^{* *}$ & $F(2,244)=.01$ & $F(2,244)=1.18$ \\
\hline Vicarious chapters & $33.65(5.38)$ & $34.22(5.58)$ & $\eta_{\mathrm{p}}^{2}=.10[.04, .17]$ & $\eta_{\mathrm{p}}^{2}<.001[.00, .00]$ & $\eta_{\mathrm{p}}^{2}=.01[.00, .04]$ \\
\hline Famous persons & $33.62(5.26)$ & $34.06(5.33)$ & & & \\
\hline \multicolumn{6}{|l|}{ Study 3} \\
\hline Personal chapters & $33.22(4.75)$ & $34.72(4.56)$ & $F(1,281)=30.61^{* *}$ & $F(2,281)=.34$ & $F(2,281)=17.02^{* *}$ \\
\hline Vicarious chapters & $33.06(4.85)$ & $34.16(5.17)$ & $\eta_{\mathrm{p}}^{2}=.10[.04, .17]$ & $\eta_{\mathrm{p}}^{2}=.002[.00, .02]$ & $\eta_{\mathrm{p}}^{2}=.11[.05, .18]$ \\
\hline Country history & $33.62(4.34)$ & 33.27 (4.73) & & & \\
\hline
\end{tabular}

Note. Self-esteem score reflects the score summed up across the 10 items (ranging from 1 to 4 each). Possible range of self-esteem: $10-40.95 \% \mathrm{CI}$ is presented in brackets.

${ }^{*} p<.05 .{ }^{* *} p<.001$.

We then determined whether emotional tone and self-change connections related to change scores for self-esteem and found no significant correlations ( $r s(133)$ from -.08, $95 \%$ CI $[-.25, .09]$ to $.04,95 \%$ CI $[-.13, .21]$, ps $>.35)$. For the control group writing about famous persons, we explored the correlation between the sum score of the four identification items with change scores in self-esteem and found no significant relation, $r(117)=$ $-.07,95 \%$ CI $[-.25, .11], p=.427$. In short, none of the measured variables were related to an increased benefit stemming from the two writing tasks.

In summary, participants who wrote about their personal chapters increased in state self-esteem while this was less pronounced among participants who wrote about famous persons. As such, the results replicate findings from previous studies (Turner et al., 2021; Steiner et al., 2019), while demonstrating that the effect is also found when using an online format. The beneficial effect of writing was not significantly related to any of the measured differences in the content of chapters. Individuals who wrote about positive chapters did not benefit more than individuals who wrote about less positive chapters. This seems to indicate that it is telling the story, rather than any specific type of story

3) We found significant interactions for positive mood for Studies 1 and 3 (with a significant before to after increase only for the personal chapters condition), see Supplementary Materials 
that boosts self-esteem. This leads us to our main question: Does it matter whose story is told? Can reflecting on vicarious life stories for parents bring similar self-esteem benefits?

\section{Figure 1}

State Self-Esteem Before and After the Experimental Manipulation in Studies 1-3

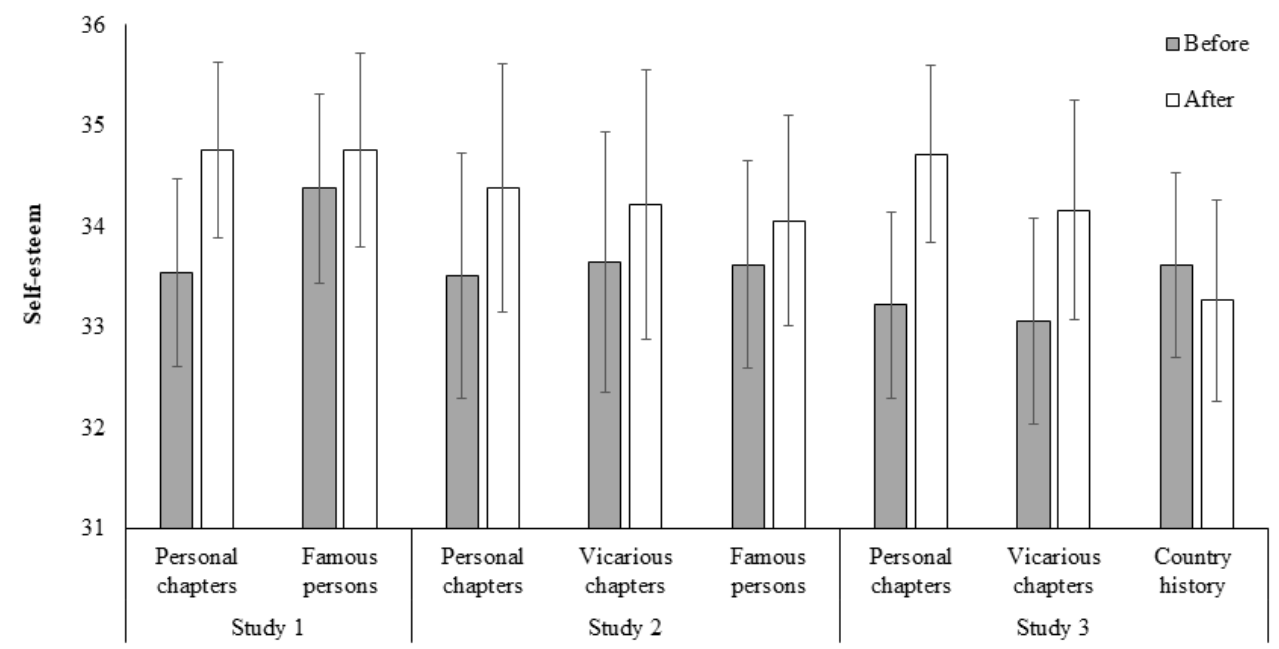

Note. Self-esteem score reflects the score summed up across the 10 items (ranging from 1 to 4 each). Possible range of self-esteem: 10-40. Error bars reflect the 95\% CI for the mean.

\section{Study 2}

Vicarious life stories serve important functions. They aid perspective-taking and understanding of close others, contributing to relationship quality (Harake et al., 2020a; Panattoni \& Thomsen, 2018). Further, they hold life lessons that may shape the construction of personal life stories (McLean, 2015; Merrill \& Fivush, 2016; Thomsen \& Pillemer, 2017). Vicarious life stories for close others are intertwined with personal life stories, as these vicarious stories are constructed to support the plots and self-images in personal life stories (Panattoni et al., 2021). As such, writing about vicarious life story chapters for a parent may boost self-esteem by contributing to the sense that one understands her/him and by indirectly bringing order and meaning to one's personal life story. To explore this possibility, we asked participants in Study 2 to either write about chapters for the parent with whom they felt closest (our vicarious life story chapters condition), about personal chapters, or about famous persons (control condition). 


\section{Method}

The study's expected sample size, hypotheses, and analyses were preregistered (see Supplementary Materials). Data scripts and materials can also be found in Supplementary Materials.

\section{Participants and Recruitment}

We had planned to recruit 100 participants for each condition to allow for the detection of a small-to-medium effect size in the main analysis. However, as pre-registered, the study was conducted as a part of a research method course with a hard deadline. Data collection was closed before reaching our planned sample size. Two hundred forty seven participants were included in this study (77 in the personal chapter condition, 69 in the vicarious chapter condition, and 101 in the control condition; note that we only analyzed data from participants who had four valid chapter/person descriptions and complete self-esteem data and excluded 127 incomplete responses). With this sample size, we are able to detect small-to-medium effects (the predicted within-between interaction) of $f$ $>.11$ (power $=.90$, correlation among repeated measures .50 , alpha-level .05, two-tailed). Participants consisted of students in the research methods course as well as additional participants they were asked to recruit (two per student with at least one being male). Demographic information is displayed in Table 1.

\section{Materials and Procedure}

The materials and procedure were modelled after Study 1 and here we only note divergences. The participants were sent an email with a link to an electronic questionnaire. They were randomly prompted to write about four personal chapters, four vicarious chapters for the parent to which they felt the closest, or four famous persons.

The instructions for personal chapters and famous persons were similar to Study 1. Participants writing about vicarious life story chapters were asked to select the parent they felt closest to and indicate whether this was their mother or father. They were given an instruction paralleling that of the personal chapter condition, where they were asked to think about their parent's entire life course and identify four important chapters in her/his life story (see Supplementary Materials). Furthermore, for each chapter they rated the following four questions on emotional tone and parent-change connections: "To what degree would you describe the chapter as positive/negative?" and "Did the chapter change your mother/father in a positive/negative way?", all rated on a 5-point Likert-type scale ranging from 1 (not at all) to 5 (to a very high degree). Finally, participants were asked to rate their degree of identification with the parent by answering the following question on a 5-point Likert-type scale ranging from 1 (do not agree at all) to 5 (totally agree): "I think my mother/father is similar to me on some points". The item was included to explore whether higher degree of identification would relate to increased effect on state self-esteem. They also provided the age of their parent. 
The scales included were identical to those of Study 1 and the internal reliabilities were good (Cronbach's alphas $>.82)^{4}$.

\section{Results and Discussion}

Most participants writing about vicarious chapters selected their mothers' life stories $(N$ = 56; fathers' life stories $N=13)^{5}$. The mean age for the selected parent was 60.27 years $(S D=12.18)$.

To test the main hypothesis that writing about vicarious and personal chapters would increase state self-esteem, we ran a mixed two-way ANOVA (group: personal chapters versus vicarious chapters versus famous persons; time: before versus after). There was a significant main effect of time, no significant effect of group, and unexpectedly the predicted interaction was not significant (Table 2 and Figure 1). We followed up by planned comparisons of before and after scores on state self-esteem for the three conditions separately. For the personal chapter group, there was a significant increase in self-esteem, $t(76)=3.84, p<.001, d=-.44,95 \%$ CI $[-.67,-.20]$, and this was also the case for the vicarious life chapter group, $t(68)=2.24, p=.028, d=-.27,95 \%$ CI $[-.51,-.03]$. For the famous person group, the effect was also significant, $t(100)=2.66, p=.009, d=$ $-.27,95 \%$ CI [-.46, -.07]. When controlling for mood change (via the PANAS) ${ }^{3}$, the main effect of time remained significant, $F(1,203)=19.33, p<.001, \eta_{\mathrm{p}}^{2}=.087$, and the two other effects remained non-significant, $F \mathrm{~s}(2,203)=.50$ and .43 , $p s>.60)$.

We then tested whether change scores for self-esteem were related to emotional tone and self/parent-change connections. No significant correlations were observed with respect to personal chapters, $r \mathrm{~s}(75)$ from $-.17,95 \% \mathrm{CI}[-.38, .06]$ to $.17,95 \% \mathrm{CI}[-.06, .38]$, or vicarious chapters, $r s(67)$ from $-.08,95 \%$ CI $[-.31, .16]$ to $.01,95 \%$ CI $[-.23, .25]$. We correlated the item measuring identification with parent to explore whether it related to the effect on self-esteem for the vicarious life chapter condition, but found no significant relationship, $r(67)=.10,95 \%$ CI $[-.14, .33], p=.43$. For the control group writing about famous persons, we explored whether the sum score of the four identification items correlated with change scores in self-esteem and found no significant relation, $r(99)=.07$, $95 \%$ CI $[-.13, .26], p=.52$. In short, as was the case in Study 1 , none of the measured variables were related to benefitting more from the three writing tasks.

In summary, the predicted condition x self-esteem increase interaction was not found. Participants writing about personal and vicarious chapters did show increases in self-esteem, but participants in the control group who wrote about famous persons also showed an increase in self-esteem. In fact, the pattern indicates that the non-significant interac-

4) We also included measures of attachment and narcissism at the very end of the study, but do not report details here, as they are not relevant for the present purpose.

5) We explored gender differences in effects of writing about vicarious life stories for mothers (the $\mathrm{N}$ for fathers was too low to allow meaningful gender comparisons). We found no significant differences, see Supplementary Materials. 
tion could be the result of a significant increase in self-esteem within the control group, implying that this group did not act as a neutral comparison. This interpretation aligns with Study 1 results where the control group increased in self-esteem to a marginally significant degree. Previous studies have indicated that thinking about favorite celebrities can carry benefits (Derrick et al., 2008) and hence writing about famous persons may be a less than ideal control condition. This may be particularly so, given that our participants seemed to focus on positive public figures (e.g., artists, sports stars, and political figures that they admired). Hence, in Study 3, we adopted a different task for the control condition to provide a neutral comparison against which potential increases in self-esteem for the two life story conditions could be compared.

\section{Study 3}

In Study 3, we examined potential beneficial effects of writing about personal and vicarious chapters. Based on the findings pertaining to the control condition used in Studies 1 and 2, in Study 3, we asked participants in the control condition to write about the history of countries (rather than famous persons). This control task was chosen because it involves narrative thinking similar to the two experimental tasks, while not involving person narratives.

Further, we modified the instructions for writing about personal and vicarious chapters in an attempt to strengthen a potential effect. Inspired by the expressive writing paradigm (Pennebaker \& Seagal, 1999) and research on value-confirmation (Steele \& Liu, 1983), we adapted the instruction to invite participants to write about thoughts, emotions, and values, as narrating internal states and value-confirmation may be mechanisms explaining the positive effect on self-esteem (Steiner et al., 2019). In addition, we asked participants to write about three rather than four chapters. In Studies 1 and 2, we had observed that several would-be participants were excluded because they were unable or unwilling to describe four chapters. By reducing the number of chapters to three, we would retain more participants in the analyses and counter potential negative effects on self-esteem arising from difficulties identifying four important life chapters (be they personal or vicarious).

\section{Method}

The study's expected sample size, hypotheses, and analyses were preregistered (see Supplementary Materials). Data scripts and materials can also be found in Supplementary Materials. 


\section{Participants and Recruitment}

As was the case in Study 2, we had planned to recruit 100 participants for each condition. However, as pre-registered, the study was conducted as a part of a research method course with a hard deadline, and we closed data collection before reaching the planned total of 300 participants. All in all, 284 participants were included (105 in the personal chapter condition, 90 in the vicarious chapter condition, and 89 in the control condition, note that we only analyze data from participants who had three valid chapter/country history descriptions and complete self-esteem data, and excluded 173 incomplete responses). With this sample size, we are able to detect small-to-medium effects (the predicted within-between interaction) of $f>.10$ (power $=.90$, correlation among repeated measures .50, alpha-level .05, two-tailed). Participants were recruited in a manner akin to Studies 1 and 2. Each student was asked to enroll two additional participants, at least one man. Demographic information appears in Table 1.

\section{Materials and Procedure}

Materials and procedure were modelled after Study 2 with the exceptions noted above, and here we only note divergences. The instructions for personal and vicarious chapters were similar to those of Study 2, except that we asked for three (rather than four) chapters. Participants were further invited to "include information about people, activities, emotions, and thoughts that you associated with the chapter". The first follow-up question on chapters also asked participants to reflect on what the chapter said about what was important to them (see Supplementary Materials). The participants in the control condition were asked to write about the history of three countries: USA, France, and England (these countries were selected because we assumed that most Danish students would be familiar with their history). The instructions further stated that they could write about anything they chose from far back into the past and up to year 2000 (to avoid corona-related events); that they should be as specific, detailed and factual as possible (they were asked to imagine that they were historians writing about these events). For each country, they were further asked to include factual information about people, places, and actions that were a part of the history of the country, think about what they wished to write about before starting, and to spend at least 10 minutes writing. In order to parallel the two experimental conditions, participants were then asked to elaborate in response to two questions concerning what the respective history said about the identity of the country and what was important to the country, and whether the history of the country described was connected to the history of other countries. They were then asked to rate four questions about each country: "To what degree would you evaluate the events as positive/negative for the country?" and "Did the events change the country in a positive/negative way?", all rated on a 5-point Likert-type scale ranging from 1 (not at all) to 5 (to a very high degree). 
The scales included were similar to Studies 1 and 2. The internal reliabilities were good (Cronbach's alphas $>.82)^{4}$.

\section{Results and Discussion}

As was the case in Study 2, most participants writing about vicarious chapters selected their mothers' life stories $(N=69 \text {; fathers' life stories } N=21)^{5}$. The mean age for the selected parent was 56.92 years $(S D=9.43)$.

To test the main hypothesis that writing about vicarious and personal chapters would increase state self-esteem, we ran a mixed two-way ANOVA (group: personal chapters versus vicarious chapters versus country history; time: before versus after). There was a significant main effect of time, no significant effect of group, and the predicted significant interaction (Table 2 and Figure 1). We followed up by a planned comparison of before and after scores on state self-esteem for the three conditions separately. For the personal chapter group, there was a significant increase in self-esteem, $t(104)=7.39, p$ $<.001, d=-.72,95 \%$ CI $[-.94,-.51]$, and this was also the case for the vicarious chapter group, $t(89)=5.08, p<.001, d=-.54,95 \%$ CI $[-.76,-.31]$. For the country history group, the reduction in self-esteem did not reach significance, $t(88)=1.22, p=.226, d=.13$, 95\% CI $[-.08, .34])$. When controlling for mood change (via the PANAS) ${ }^{3}$, the interaction remained significant, $F(2,277)=8.79, p<.001, \eta_{\mathrm{p}}^{2}=.060$; effect of time: $F(1,277)=26.80, p$ $<.001, \eta_{\mathrm{p}}^{2}=.088$; effect of group: $F(2,277)=.58, p=.559, \eta_{\mathrm{p}}^{2}=.004$.

We then tested whether change scores for self-esteem were related to emotional tone and self/parent-change connections and found no significant correlations, $r s(103)$ from $-.07,95 \%$ CI $[-.26, .12]$ to $.12,95 \%$ CI $[-.07, .30]$ for personal chapters and $r s(88)$ from $-.07,95 \%$ CI $[-.27, .14]$ to $.07,95 \%$ CI $[-.14, .27]$ for vicarious chapters). We correlated the item measuring identification with parent to explore whether it related to the effect on self-esteem for the vicarious chapter condition, but found no significant relationship, $r(88)=-.05,95 \%$ CI $[-.25, .16], p=.671$. In short, none of the measured variables were related to benefitting more from the two chapter tasks.

In summary, we garnered support for our hypothesis that writing about both vicarious chapters for a close parent and personal chapters increased state self-esteem. As such, Study 3 both replicates and extends Study 1 and previous studies (Steiner et al., 2019; Turner et al., 2021). The effect size for vicarious life story chapters was smaller than the one for personal life story chapters, indicating that the two conditions may not be equivalent in their effects. None of the measured chapter characteristics (emotional tone and self/parent-change connections) were related to changes in self-esteem. That is, participants' improvement was not conditional on writing about positive (or negative) chapters, which is similar to previous studies (Steiner et al., 2019). 


\section{General Discussion}

The main purpose of our studies was to determine whether writing about vicarious life stories for close others boosts state self-esteem in a manner comparable to writing about one's own chapters. Having validated an online experimental paradigm in Study 1, this possibility was tested and confirmed in Studies 2 and 3. Below, we discuss the novel findings regarding vicarious life stories.

\section{Narrating Close Others' Lives Brings Psychological Advantages}

Our finding that writing about the vicarious life stories of parents carry benefits for self-esteem, similar to that of writing about personal life stories, is broadly consistent with the idea that making meaning through story construction (be they the author's own or those of close others) fosters psychological adjustment (McAdams, 2013). The studies extend previous literature on vicarious and intergenerational stories, which have shown that story characteristics relate to well-being (Harake et al., 2020b; Merrill \& Fivush, 2016; Thomsen \& Vedel, 2019). The important difference between the previous and the present studies is that we examined effects of the narration process rather than particular thematic and structural features of narratives, in relation to psychological adjustment. The difference between our approach and previous studies is also apparent in the lack of significant relations between the content of vicarious life stories and improvements in self-esteem in both Studies 2 and 3. This is similar to the previous studies, which found no associations between writing about particular content of personal chapters and self-esteem increase (Steiner et al., 2019). This is likely explained by our focus on the process of narration and changes in self-esteem (intervention) versus observing relations between life story features and positive outcomes (assessment).

Why would writing about parents' life stories increase self-esteem? We did not examine potential mechanisms but speculate that the effects may arise through two pathways: 1) improved understanding of the close other (parent) and 2) indirect effects on personal life stories. As a part of writing about parents' chapters, individuals reflected on the meaning of the chapters in terms of parents' values and identity. Forming rich mental representations of the close others that populate individuals' social world is a key process involved in maintaining closeness, negotiating conflict, and ensuring smooth collaboration (Harake et al., 2020a; Panattoni \& Thomsen, 2018). Constructing vicarious life stories is a part of sophisticated and individualized perspective-taking, and they likely organize and infuse with meaning the variety of social interaction taking place over the course of close relationships. As individuals gain a sense that they understand the close other better through reflecting on her/his life story, they may experience heightened self-esteem.

Additionally, reflecting on parents' life stories may have invited parallel thoughts about personal life stories. Several authors agree that personal and vicarious stories are 
closely intertwined (Reese et al., 2017; Thomsen \& Pillemer, 2017). Individuals can learn from parents' life stories (McLean, 2015; Merrill \& Fivush, 2016) and may shape their personal life stories to mirror or diverge from parents' life stories (Thomsen \& Vedel, 2019). Hence, reflecting on the meaning of parents' chapters could simultaneously evoke thoughts about the meaning of one's own chapters.

Future studies can tease apart these explanations by introducing additional experimental conditions and outcome variables. For example, it would be useful to examine whether the vicarious life story condition leads to a sense of understanding the close other and/or oneself.

\section{Life Stories and Intervention}

Importantly, we demonstrated experimentally that writing about vicarious life stories can improve self-esteem, suggesting a causal relation between life story reflection and psychological adjustment. The latter is a key development in life story research generally, but in vicarious life story research particularly, as much research is non-experimental (Adler et al., 2016; Merrill \& Fivush, 2016; Thomsen et al., 2020). To better understand the beneficial effects of life stories and to support the development of narrative interventions, the field could embrace experimental research studying the micro-processes involved in narration and psychological adjustment. We offer the current paradigm as a useful starting point for conducting such controlled research, as instructions in the life story conditions can be varied systematically to examine the impact of potential adaptive narrative processes, such as positive meaning, coherence, and emotional integration (Adler et al., 2016; Dunlop, 2021; Habermas, 2019). Such conditions can be compared to more open instruction to test whether there are selective benefits to certain types of stories or whether it is the storying process as such that is important.

If the present findings for vicarious life stories are replicated, it would suggest that crafting life stories for close others could be a focus for narrative interventions. Presently, these emphasize sharing personal stories (Pinquart \& Forstmeier, 2012; White \& Epston, 1990), but as argued above, rich and complex understanding of close others supported by vicarious life story construction may hold advantages for psychological adaptation that go beyond those conferred by personal life stories. The insights and methods from vicarious life story research may offer routes to further developing narrative interventions (Thomsen et al., 2021).

\section{Limitations and Future Directions}

We acknowledge that part of our sample were students from psychology, although we enriched it with people from the broader population. Nonetheless, it remains unclear whether the results replicate in different samples and also in non-WEIRD populations. Furthermore, as is clear from Study 2, writing about famous persons can also hold 
advantages. Although participants were not instructed to write life stories for famous persons, the finding points to the possibility that the effect may not be limited to close others and to life stories. Indeed, a central question arising from the present research is the boundary conditions of the effect. Does the benefit for adjustment stem from writing about valued persons (self, close others, admired distant others) or would it also extend to writing about other valued topics (nature, peace) or even disliked persons and topics (rivals, pollution)? Is the construction of narrative crucial or would associative writing and reflection work similarly? Future studies could examine whether the effect varies with topic and story-like quality.

\section{Conclusion}

In the first experimental studies to examine the benefits of writing about vicarious life stories for close others, we found that participants who wrote about chapters for their parents increased in state self-esteem. This effect parallels the one found for personal life story chapters and is consistent with the idea that constructing vicarious life stories may support understanding of close others and oneself, facilitating psychological adjustment. 
Funding: The authors have no funding to report.

Acknowledgments: The authors have no additional (i.e., non-financial) support to report.

Competing Interests: The authors have declared that no competing interests exist.

Author Contributions: Dorthe Kirkegaard Thomsen-Idea, conceptualization | Design planning | Resource provision (materials, participants, etc.) | Research implementation (software, hardware, etc.) | Data collection | Data management (storage, curation, processing, etc.) | Visualization (data presentation, figures, etc.) | Data analysis | Validation, reproduction, checking | Writing | Feedback, revisions | Project coordination, administration. Stefan Pfattheicher-Idea, conceptualization | Design planning | Resource provision (materials, participants, etc.) | Research implementation (software, hardware, etc.) | Data collection | Visualization (data presentation, figures, etc.) | Data analysis | Validation, reproduction, checking | Writing | Feedback, revisions. William L. Dunlop-Idea, conceptualization | Visualization (data presentation, figures, etc.) | Data analysis | Validation, reproduction, checking | Writing | Feedback, revisions.

Ethics Statement: No ethical issues and/or ethics approvals need to be disclosed.

Author Note: William L. Dunlop (last author) passed away during the revision of the manuscript. We are deeply saddened by the loss of our colleague and friend. We will miss his generosity, his passion for narrative identity, and his truly collaborative approach to research.

Related Versions: No other previously published versions of this manuscript exist in part or in whole.

Data Availability: The full data set (for Study 1-3) is not available, as national data sharing rules do not presently allow this.

\section{Supplementary Materials}

For this article the following Supplementary Materials are available (for access see Index of Supplementary Materials below):

- $\quad$ Preregistration documentation for Study 2 and Study 3.

- Data scripts.

- Additional materials.

\section{Index of Supplementary Materials}

Thomsen, D. K., Pfattheicher, S., \& Dunlop, W. L. (2019). Supplementary materials to: Authoring esteem: Writing about vicarious and personal life story chapters boosts state self-esteem [Preregistration documentation for Study 2]. AS PREDICTED. https://aspredicted.org /u9ta4.pdf 
Thomsen, D. K., Pfattheicher, S., \& Dunlop, W. L. (2020). Supplementary materials to: Authoring esteem: Writing about vicarious and personal life story chapters boosts state self-esteem [Preregistration documentation for Study 3]. AS PREDICTED. https://aspredicted.org /w76jj.pdf

Thomsen, D. K., Pfattheicher, S., \& Dunlop, W. L. (2021). Supplementary materials to: Authoring esteem: Writing about vicarious and personal life story chapters boosts state self-esteem [Data scripts and additional materials]. PsychOpen GOLD.

https://doi.org/10.23668/psycharchives.5315

\section{References}

Adler, J. M., Lodi-Smith, J., Philippe, F. L., \& Houle, I. (2016). The incremental validity of narrative identity in predicting well-being: A review of the field and recommendations for the future. Personality and Social Psychology Review, 20(2), 142-175. https://doi.org/10.1177/1088868315585068

Alea, N., \& Bluck, S. (2007). I'll keep you in mind: The intimacy function of autobiographical memory. Applied Cognitive Psychology, 21(8), 1091-1111. https://doi.org/10.1002/acp.1316

Baumeister, R. F. (1999). Self-concept, self-esteem, and identity. In V. J. Derlega, B. A. Winstead, \& W. H. Jones (Eds.), Personality: Contemporary theory and research (pp. 339-375). Nelson-Hall Publishers.

Bruner, J. (1990). Acts of meaning. Harvard University Press.

Campbell, J. D., Trapnell, P. D., Heine, S. J., Katz, I. M., Lavallee, L. F., \& Lehman, D. R. (1996). Selfconcept clarity: Measurement, personality correlates, and cultural boundaries. fournal of Personality and Social Psychology, 70(1), 141-156. https://doi.org/10.1037/0022-3514.70.1.141

Çili, S., \& Stopa, L. (2015). The retrieval of self-defining memories is associated with the activation of specific working selves. Memory, 23(2), 233-253. https://doi.org/10.1080/09658211.2014.882955

Derrick, J. L., Gabriel, S., \& Tippin, B. (2008). Parasocial relationships and self-discrepancies: Faux relationships have benefits for low self-esteem individuals. Personal Relationships, 15(2), 261-280. https://doi.org/10.1111/j.1475-6811.2008.00197.x

Diener, E., Oishi, S., \& Lucas, R. E. (2003). Personality, culture, and subjective well-being: Emotional and cognitive evaluations of life. Annual Review of Psychology, 54, 403-425. https://doi.org/10.1146/annurev.psych.54.101601.145056

Dunlop, W. L. (2015). Contextualized personality, beyond traits. European fournal of Personality, 29(3), 310-325. https://doi.org/10.1002/per.1995

Dunlop, W. L. (2021). Everything you wanted to know about redemptive stories* (*but were afraid to ask). Journal of Research in Personality, 92, Article 104078. https://doi.org/10.1016/j.jrp.2021.104078

Frattaroli, J. (2006). Experimental disclosure and its moderators: A meta-analysis. Psychological Bulletin, 132(6), 823-865. https://doi.org/10.1037/0033-2909.132.6.823 
Habermas, T. (2019). Emotion and narrative: Perspectives in autobiographical storytelling. Cambridge University Press. https://doi.org/10.1017/9781139424615

Habermas, T., \& Bluck, S. (2000). Getting a life: The emergence of the life story in adolescence. Psychological Bulletin, 126(5), 748-769. https://doi.org/10.1037/0033-2909.126.5.748

Harake, N. R., McCoy, T. P., Lee, D., \& Dunlop, W. L. (2020a). Narrating the other: Self-other agreement of affective qualities and manifest events among personal life stories and the vicarious life stories provided by informants. Journal of Research in Personality, 89, Article 104037. https://doi.org/10.1016/j.jrp.2020.104037

Harake, N. R., Wilkinson, D. E., Sweeny, K., \& Dunlop, W. L. (2020b). Narrating the nadir: Examining personal and vicarious stories of cancer-related low points among survivors and romantic partners. Psychology \& Health, 35(10), 1268-1292.

https://doi.org/10.1080/08870446.2020.1743838

Jensen, R. A. A., Thomsen, D. K., O’Connor, M., \& Mehlsen, M. Y. (2020). Age differences in life stories and neuroticism mediate age differences in subjective well-being. Applied Cognitive Psychology, 34(1), 3-15. https://doi.org/10.1002/acp.3580

Johansson, R., \& Andersson, G. (2012). Internet-based psychological treatment for depression. Expert Review of Neurotherapeutics, 12(7), 861-870. https://doi.org/10.1586/ern.12.63

Jones, B. K., Destin, M., \& McAdams, D. P. (2018). Telling better stories: Competence-building narrative themes increase adolescent persistence and academic achievement. Journal of Experimental Social Psychology, 76, 76-80. https://doi.org/10.1016/j.jesp.2017.12.006

Lind, M., \& Thomsen, D. K. (2018). Functions of personal and vicarious life stories: Identity and empathy. Memory (Hove, England), 26(5), 672-682. https://doi.org/10.1080/09658211.2017.1395054

McAdams, D. P. (1996). Personality, modernity, and the storied self: A contemporary framework for studying persons. Psychological Inquiry, 7(4), 295-321. https://doi.org/10.1207/s15327965pli0704_1

McAdams, D. P. (2008). The life story interview [Unpublished manuscript]. Department of Psychology, Northwestern University.

McAdams, D. P. (2013). The redemptive self: Stories Americans live by (2nd ed.). Oxford University Press.

McAdams, D. P., \& McLean, K. C. (2013). Narrative identity. Current Directions in Psychological Science, 22(3), 233-238. https://doi.org/10.1177/0963721413475622

McAdams, D. P., Reynolds, J., Lewis, M., Patten, A. H., \& Bowman, P. J. (2001). When bad things turn good and good things turn bad: Sequences of redemption and contamination in life narrative and their relation to psychosocial adaptation in midlife adults and in students. Personality and Social Psychology Bulletin, 27(4), 474-485. https://doi.org/10.1177/0146167201274008

McLean, K. C. (2015). The co-authored self: Family stories and the construction of personal identity. Oxford University Press. https://doi.org/10.1093/acprof:oso/9780199995745.001.0001 
McLean, K. C., Pasupathi, M., \& Pals, J. L. (2007). Selves creating stories creating selves: A process model of self-development. Personality and Social Psychology Review, 11(3), 262-278. https://doi.org/10.1177/1088868307301034

Merrill, N., \& Fivush, R. (2016). Intergenerational narratives and identity across development. Developmental Review, 40, 72-92. https://doi.org/10.1016/j.dr.2016.03.001

Panattoni, K. W., Nielsen, K. N., \& Thomsen, D. K. (2021). Heart-followers, hero, maiden: Life story positioning within a romantic couple. Qualitative Psychology, 8(1), 30-50. https://doi.org/10.1037/qup0000147

Panattoni, K., \& Thomsen, D. K. (2018). My partner's stories: Relationships between personal and vicarious life stories within romantic couples. Memory, 26(10), 1416-1429. https://doi.org/10.1080/09658211.2018.1485947

Pasupathi, M., Wainryb, C., Mansfield, C. D., \& Bourne, S. (2017). The feeling of the story: Narrating to regulate anger and sadness. Cognition and Emotion, 31(3), 444-461. https://doi.org/10.1080/02699931.2015.1127214

Pennebaker, J. W., \& Seagal, J. D. (1999). Forming a story: The health benefits of narrative. fournal of Clinical Psychology, 55(10), 1243-1254. https://doi.org/10.1002/(SICI)1097-4679(199910)55:10<1243::AID-JCLP6>3.0.CO;2-N

Pillemer, D. B., Steiner, K. L., Kuwabara, K. J., Thomsen, D. K., \& Svob, C. (2015). Vicarious memories. Consciousness and Cognition, 36, 233-245.

https://doi.org/10.1016/j.concog.2015.06.010

Pinquart, M., \& Forstmeier, S. (2012). Effects of reminiscence interventions on psychosocial outcomes: A meta-analysis. Aging \& Mental Health, 16(5), 541-558. https://doi.org/10.1080/13607863.2011.651434

Pratt, M. W., Norris, J. E., Hebblethwaite, S., \& Arnold, M. L. (2008). Intergenerational transmission of values: Family generativity and adolescents' narratives of parent and grandparent value teaching. Journal of Personality, 76(2), 171-198. https://doi.org/10.1111/j.1467-6494.2007.00483.x

Reese, E., Fivush, R., Merrill, N., Wang, Q., \& McAnally, H. (2017). Adolescents' intergenerational narratives across cultures. Developmental Psychology, 53(6), 1142-1153. https://doi.org/10.1037/dev0000309

Rosenberg, M. (1965). Society and the adolescent self-image. Princeton University Press. https://doi.org/10.1126/science.148.3671.804

Ryff, C. D. (2014). Psychological well-being revisited: Advances in the science and practice of eudaimonia. Psychotherapy \& Psychosomatics, 83, 10-28. https://doi.org/10.1159/000353263

Smorti, A., \& Fioretti, C. (2016). Why narration changes memory: A contribution to an integrative model of memory and narrative processes. Integrative Psychological \& Behavioral Science, 50, 296-319. https://doi.org/10.1007/s12124-015-9330-6

Steele, C. M., \& Liu, T. J. (1983). Dissonance processes as self-affirmation. Fournal of Personality and Social Psychology, 45(1), 5-19. https://doi.org/10.1037/0022-3514.45.1.5 
Steiner, K. L., Pillemer, D. B., \& Thomsen, D. K. (2019). Writing about life story chapters increases self-esteem: Three experimental studies. Fournal of Personality, 87(5), 962-980. https://doi.org/10.1111/jopy.12449

Thomsen, D. K. (2009). There is more to life stories than memories. Memory (Hove, England), 17(4), 445-457. https://doi.org/10.1080/09658210902740878

Thomsen, D. K., Holm, T., Jensen, R. A. A., Lind, M., \& Pedersen, A. M. (2021). Storying mental illness and personal recovery (Book manuscript in revision after review).

Thomsen, D. K., Panattoni, K. W., Allé, M. C., Wellnitz, K. B., \& Pillemer, D. P. (2020). Vicarious life stories: Examining relations to personal life stories and well-being. Fournal of Research in Personality, 88, Article 103991. https://doi.org/10.1016/j.jrp.2020.103991

Thomsen, D. K., \& Pillemer, D. B. (2017). I know my story and I know your story: Developing a conceptual framework for vicarious life stories. Journal of Personality, 85(4), 464-480. https://doi.org/10.1111/jopy.12253

Thomsen, D. K., Steiner, K. L., \& Pillemer, D. B. (2016). Life story chapters: Past and future, you and me. JARMAC, 5(2), 143-149. https://doi.org/10.1016/j.jarmac.2016.03.003

Thomsen, D. K., \& Vedel, A. (2019). Relationships among personal life stories, vicarious life stories about mothers and fathers, and well-being. Identity, 19(3), 230-243.

https://doi.org/10.1080/15283488.2019.1635476

Turner, A. F., Cowan, H. R., Otto-Meyer, R., \& McAdams, D. P. (2021). The power of narrative: The emotional impact of the life story interview. Narrative Inquiry.

https://doi.org/10.1075/ni.19109.tur

Watson, D., Clark, L. A., \& Tellegen, A. (1988). Development and validation of brief measures of positive and negative affect: The PANAS scales. Journal of Personality and Social Psychology, 54(6), 1063-1070. https://doi.org/10.1037/0022-3514.54.6.1063

White, M., \& Epston, D. (1990). Narrative means to therapeutic ends. W.W. Norton \& Company.

\section{eapp}

Personality Science (PS) is an official journal of the European Association of Personality Psychology (EAPP).
(4) leibniz-psychology.org

PsychOpen GOLD is a publishing service by Leibniz Institute for Psychology (ZPID), Germany. 